\title{
交流高電圧印加によるW/0 エマルジョンの解乳化
}

\author{
井 野 一 \\ 群馬工業高等専門学校* \\ 今 石 宣之・宝 沢 光 紀 \\ 藤 縄 勝 彦 \\ 東北大学 非水溶液化学研究所**
}

\begin{abstract}
$\mathrm{W} / \mathrm{O} / \mathrm{W}$ 型乳化液膜による抽出プロセスの問題点は, その最終段階すなわち $\mathrm{W} / \mathrm{O}$ エマルジョン の破壊（解乳化）操作にあると思われる. 本報は交流を用いた電気的方法の, 解乳化操作としての 有効性を検討するとともにその基本的特性を解明することを目的とする.

食塩水と, Span 80 を 4 vol \% 含むケロシン溶液とを回転式ディスパーザで䚌挥して試料ェマ ルジョンを作製した. 分散水滴の平均径 $\tilde{d}_{p}$ は $3.2 \sim 4.7 \mu \mathrm{m}$ の範囲にある. このエマルジョンは遠 心力あるいは昇温による解乳化試験に対して極めて安定であった. エマルジョン層内に挿入したガ ラス製の非導電性電極と, エマルジョン層の下部にある水相との間に $1 \sim 12 \mathrm{kV}$ の交流電圧を印加 することによってェマルショョンの安定性は極端に低下し, 清澄な水相が得られた. 主要な因子と清 澄水生成速度 $V$ との関係は次式で表された.
\end{abstract}

$$
\begin{aligned}
& V \propto H \cdot E^{n} \cdot \tilde{d}_{p}^{3} \cdot\left(\frac{\mu^{*}-\mu}{\mu^{*}-\mu_{c}}\right), \quad n= \begin{cases}0.5 & \left(E<E_{T}\right) \\
2.0 & \left(E_{T}<E\right)\end{cases} \\
& \mu^{*} \propto E^{-1 / 3} \cdot \tilde{d}_{p}{ }^{-1 / 3}
\end{aligned}
$$

ここで, $H$ は電極間隔, $E$ は印加電圧, $\mu$ は土マルジョンの粘度, $\mu_{c}$ は油相の粘度であり, $E_{T}$ は遷移電圧でその值は $6 \sim 8 \mathrm{kV}$ である.

結論として, 水滴の直径が $1 \mu \mathrm{m}$ 以上であるならば, W/O エマルジョンは交流高電压印加法によ って解乳化されることがわかった。

\section{緒言}

最近 $\mathrm{W} / \mathrm{O} / \mathrm{W}$ 型乳化液膜を利用する抽出操作が注目 されている.この方式の分離プロセスを連続的に操作す るには，抽出後の W/O エマルジョンを破壊（解乳化） して油水分離し，水相中の抽質を回収する必要がある.

連続操作を行うためには，界面活性剂（乳化剂）を化 学的に分解する物質や凝集促進剤あるいは油水を可溶化 する溶媒などを添加する方法は好ましくない，また乳化 剤を添加した W/O エマルションは一般に安定で, 遠心 分離や加熱による解乳化はエネルギー消費量が多いわり には分離効率が小さい.

Martine と Davies2) は，エネルギー効率および分離 効率いずれの観点からも, 静電気的な解乳化法が最適で あると報じている。しかし，高電圧印加による W/O エ マルショョンの解乳化は, 原油の脱塩処理装置に拈いて大 規模に応用されているにもかかわらず，その設計基準は

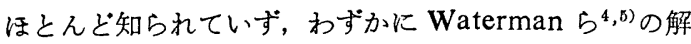
説がみられるだけである.

* $\overline{\mathbf{T}} 371$ 前橋市鳥羽町 580

** 干980 仙台市片平 2-1-1
したがって，W/O/W 型乳化液膜法で使用されるよう な, 分散水相体積分率が比較的高く, 乳化剤で安定化さ れた W/O エマルジョンを高電圧印加により解乳化する 方法に関する基礎的な資料を得る必要がある.この点に 関しては北川ら ${ }^{1)}$ の資料があるが詳細は不明である。そ こで，著者らは小型の回分式装置を用いて $\mathrm{W} / \mathrm{O}$ ェマル ジョンの解乳化実鈳を行った. その結果, 清澄水相の生 成速度に及ぼす電極間隔，印加電圧，水相体積分率拉上 び粒子径の影響について有用な知見を得たので報告す る.

\section{1. 実験装置と実験方法}

実験に使用した回分式装置の概略を Fig. 1 に示す. 装置本体は，黄銅製の底板を取り付けた内径 $9 \mathrm{~cm}$, 高 さ $40 \mathrm{~cm}$ のアクリル樹脂製の円筒である. 筒壁にあけ た穴からガラス製の非導電性電極（以後ガラス電極と呼 ぶ）を插入した。

あらかじめ槽底に高さ $5 \mathrm{~cm}$ まで $3 \mathrm{wt} \%$ 食塩水を満 たし，その上に後述する方法で作製した試料ェマルジョ ンを $1 \mathrm{dm}^{3}$ (あるいは $2 \mathrm{dm}^{3}$ ) 加える. 直径 $3 \mathrm{~cm}$ の 2 枚 羽根を $7 \mathrm{~cm}$ 間隔で 4 段取り付けたアクリル樹脂製の穓 


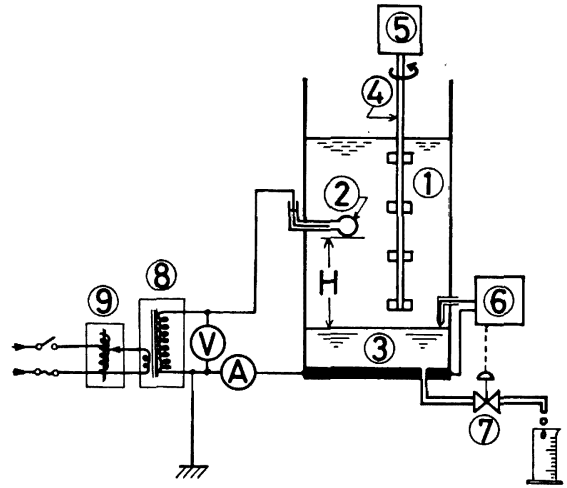
(1) Emulsion
(5) Geared motor
(2) Glass electrode
(6) Level controller
(3) $\mathrm{NaCl}$ solution
(7) Solenoid valve
(opposing electrode)
(4) Stirrer
(8) Neon-sign transformer
(9) Slidax

Fig. 1 Experimental apparatus

拌棒をエマルジョン相内に挿入し，减速機を介してモー タで回転させ覺拌した.

ネオントランスによって得た $50 \mathrm{~Hz}$ の交流高電圧を ガラス電極と黄銅製底板との間に印加するとェマルジョ ン相内で大きな水滴が形成され沈降して底部の清澄水量 が増加する. 真空管式りレー回路と電磁弁を用いて, 清 澄水面位を一定に保ち, 流出した清澄水量をメスシリン ダで測定した. ガラス電極の下端と清澄水面との距離を 電極間隔と定義すると，電極間隔は実験期間中常に一定 に保たれている。

ガラス電極は, 外径 $5 \mathrm{~mm}$ のパイレックスガラス管 の管端を直径 $1.5 \mathrm{~cm}$ の球状に吹いたものである. 球状 部のガラスの厚さ $\delta$ がでさるだけ均一なものを選んで害 験に使用した．電極内部には飽和食塩水を満たし，内部 に差し込んだ銅線を介して電源回路へ接続した.

実験はすべて $298 \pm 0.5 \mathrm{~K}$ で行った。

\section{2. 試料エマルジョン}

実験に用いたエマルジョンは, 乳化剂 Span 80 を vol\% $(5 \mathrm{wt} \%)$ 含むケロシン溶液（以後単にケロシン溶 液と呼ぶ）を油相とし，食塩水（濃度 $C_{E}=0.51,0.17$, 0.017* および $0 \mathrm{~mol} / \mathrm{dm}^{3}$ ) を分散相とする W/O エマ ルジョンである.なお,一部の実験では $\mathrm{HCl}$ 水溶液を 分散相とした W/O エマルジョンを用いた.

\section{2・1 エマルジョンの作製法}

所定濃度の水溶液 $1 \mathrm{dm}^{3}$ とケロシン溶液 $1 \mathrm{dm}^{3}$ を内

*それぞれ，3.0,1.0 および 0.1 wt\% に相当する。

** 乳化直後のエマルジョンに高笔圧を印加した時の解乳化速度は，乳 化後 30 分間静置したエマルジョンのそれよりも5 30\% 大きな值 を示す.これは，微小水滴表面人の Span 80 の吸着是が経時的に增 加し，エマルジョンを安定化するためと考えられる。静瞋時間が 30 分 3時間程度の籍囲内では解孚化速度はほほ一定値を示す。
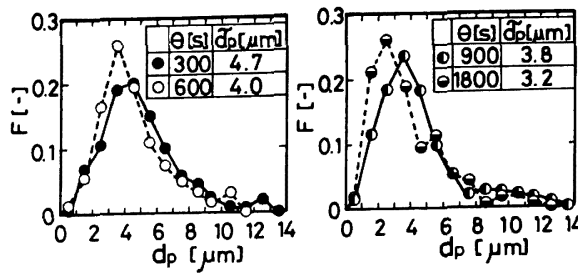

Fig. 2 Size distribution of dispersed water droplets

径 $16 \mathrm{~cm}$ の円筒容器に入れ, YSTRAL WG-20T 型回 転ロータ式ディスパーザ（三田村理研（株）ラボディスパ ーザ）を用いて乳化した．ロータの回転速度は $167 \mathrm{rps}$ とし，攪拌時間 $\theta$ を变えてェマルションの性質を变化さ せた. このエマルジョンを同じ Span 80 濃度のケロシ ン溶液で希釈し，粒径分布が同じで分散水相体積分率 $\phi$ のみが異なるエマルジョンを作り実験に供した。なお， $\phi$ が 0.5 以上のエマルジョンは，最初からその割合で用 意した合計 $2 \mathrm{dm}^{3}$ の二液体を上述のディスパーザで乳化 したものを使用した.

実験結果の再現性を確保するため, 乳化後 $30 \sim 60$ 分 間恒温水槽中で静置したエマルジョンを使用した**.

\section{$2 \cdot 2$ 粒径分布}

微量のエマルジョンをケロシンで希釈し，遠心式自動 粒度分布測定装置（堀場 (株)CAPA-500 型)を用い，光 透過法によって体積基準の粒径分布を求めた。頻度分布 の測定粒子径間隔は $1 \mu \mathrm{m}$ とした。平均粒子径 $\tilde{d_{p}}$ とし てはメディアン径を用いた.

乳化時のディスパーザの運転時間 $\theta$ による粒径分布の 変化の様子を Fig. 2 に示す. $\theta$ の増加とともに $\tilde{d_{p}}$ は 減少する. $\theta$ が 20 分以上になると, 粒径分布はほぼ対 数正規分布に従らようになる.

\section{$2 \cdot 3$ エマルジョンの粘度}

毛細管粘度計および円錘平板型回転粘度計（東京計器 （株）ELD 型）を用いて試料エマルジョンの流動特性を 調べた.

本実験に用いた W/O エマルジョンは高剪断速度下で はニュートン流体的挙動を，低剪断速度下では擬塑性流 体的挙動を示す非ニュートン流体である．水相体積分率 $\phi$ の増加とともに粘性は増し, 同時に非ニュートン流体 的挙動も顕著になる. 高剪断速度域でのエマルジョンの 粘度を $\mu$, ケロシン溶液の粘度を $\mu_{\mathrm{c}}$ としたときの $\mu / \mu_{\mathrm{c}}$ の $\phi$ 依存性を Fig. 3 に示す. 図中の太い串線は Mooney 式 ${ }^{3)}$ (Eq. (1)) による推算結果である.

$$
\frac{\mu}{\mu_{\mathrm{c}}}=\frac{\sqrt{1+0.5 \phi}}{1-\phi} \exp \left(\frac{1.25 \phi}{1-\phi}\right)
$$

図から，本実験系でのエマルジョンの粘度の概略値は Eq. (1) で推算できることがわかる. しかし，後述する 実験值の相関の際には，実測の関係を用いた。 


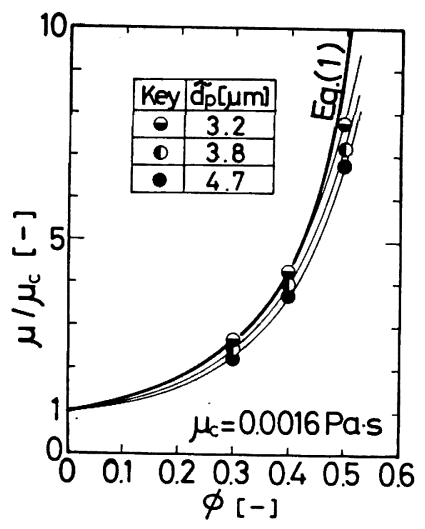

Fig. 3 Viscosity of the W/O emulsions under high shear rate

\section{$2 \cdot 4$ 遠心力による解乳化の可能性}

ディスパーザで 30 分間䚓找して作製した $\phi=0.5$ の エマルショョ (分散相は食塩水, $C_{E}=0.51 \mathrm{~mol} / \mathrm{dm}^{3}$ ) の 常温安定性を調べるため遠心力を付加した. 日立工機 (株) 18-PR-52 型遠心機と RPR-20-3 型ロータ（サン プル容器容量 $7 \mathrm{~cm}^{3}$ ) を使用し, 温度は $298 \mathrm{~K}$ に保っ た. 遠心加速度 $36,000 \times g$ に 20 分間保った後の容器中 には，上部約半分に透明なケロシン相，下部には半透明 のグリース状物質が得られるが, 解乳化による連続水相 は形成されない.グリース状物質をカールフィッシャー 法により分析した結果, その水分重量分率は 0.90 0.95 であった．遠心分離後のサンプルをそのまま静置する と, ケロシンがグリース状物質中に浸透し上面から次第 に膨潤白濁し, 長時間後（約 12 時間程度）には全体が 白濁する.これを激しく振ると再び W/O エマルジョン が得られる.この再生エマルジョンの粒径分布を Fig. 4 に示す. 原エマルジョンに比較してわずかに大粒径側に ずれる傾向を示したのみである．他の濃度の食塩水ある いは純水を内部水相としたェマルジョンでも同様な結果 が得られた. このことから, 水滴間の反撥力は強く遠心 場での合体速度は極めて小さいことがわかる.したがっ て，Span 80 によって安定化されたW/O エマルジョン の遠心力による解乳化は困難であると結論づけられる.

\section{$2 \cdot 5$ 加熱による解乳化の可能性}

$2 \cdot 4$ と同じェマルショョンを $363 \mathrm{~K} に 20$ 分間保った 場合にも連続水相は出現せず，粒径分布も Fig. 4 に示 すように加熱前の原エマルジョンと大きな差は見られな い.また，沸騰温度*に保っても水分が蒸発しつくすま で乳化状態が存続する．したがって，加熱することによ つて本研究の試料エマルショョンを解乳化し抽質を回収す ることは困難であると結論づけられる。

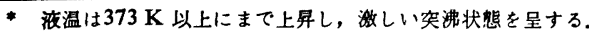

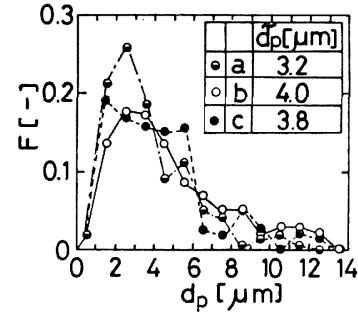

a: original emulsion

b: re-dispersed after centrifugal demulsification test (36 $000 \times g, 20 \mathrm{~min}$.)

c: after thermal demulsification test $(363 \mathrm{~K}, 20 \mathrm{~min})$

Fig. 4 Effects of centrifugal force and heating on the size distribution of dispersed water droplets

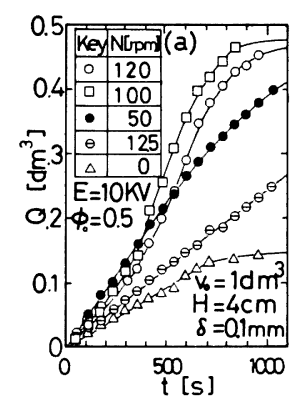

(a)

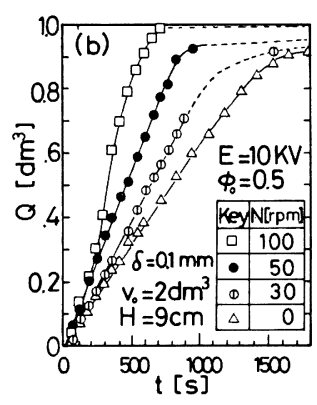

(b) (a) operated with a short distance between electrodes

(b) operated with a medium distance between electrodes

Fig. 5 Clear water production vs. time, under applied AC potential

\section{3. 交流高電圧印加による解乳化実験の結果と考察}

Fig. 1 に示した回分式実験装置に, $\tilde{d}_{p}=3.2 \mu \mathrm{m}, \phi_{0}=$ 0.5 のマルジョン(分散相は食塩水, $C_{E}=0.51 \mathrm{~mol} / \mathrm{dm}^{3}$ ) を仕込み, $10 \mathrm{kV}$ の交流電圧を印加した場合の清澄水流 出量すなわち解乳化量 $Q$ の経時測定例を Figs. 5 に示 す. Fig. 5 (a) は電極間隔 $H$ が小さい場合, 同 (b) は $H$ を増した場合の結果である.なお，エマルジョンの 仕込み量 $v_{0}$ は Fig. 5 (a) では $1 \mathrm{dm}^{3}$, (b) では $2 \mathrm{dm}^{3}$ であった。

電圧印加後, 若干の待ち時間を経たのちエマルジョンー 清澄水界面上に直径 1 数 $\mathrm{mm}$ の水滴が落下し, それが 崩壊して槽底から水が流出し始める. この待ち時間は数 秒から数十秒程度である.

槽底から流出する水はエマルジョンやケロシンを含ま ぬ清澄な水であった. しかし清澄なケロシン相を得るこ とはできなかったすすなわち，本実験装置で到達可能な 最終解乳化率 $\left(=Q / v_{0} \cdot \phi_{0}\right)$ は最高でも $99 \%$ 程度で, 通 常仕込みエマルジョン中の水分量 $\left(v_{0} \phi_{0}\right)$ の $1 \sim 5 \%$ は 乳化状態のまま残留する. 粒径分布を測定した結果, 残 留水滴の最大径は $2 \mu \mathrm{m}$ 程度で, 大部分は $1 \mu \mathrm{m}$ 以下の 微小滴であった。 


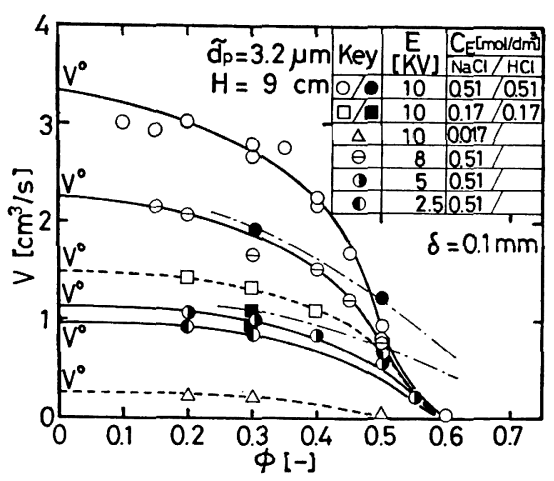

Fig. 6 Effect of the volumetric fraction of water $\phi$ on the throughout rate of the clear water $V$

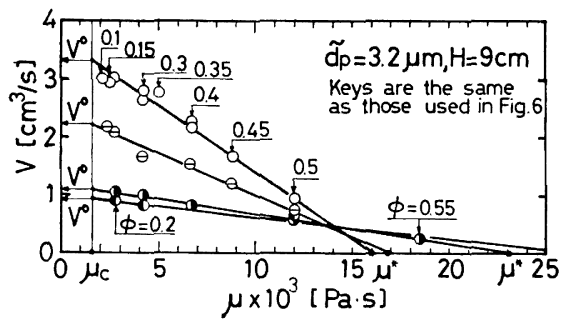

Fig. 7 Empirical correlation of $V$ with the emulsion viscosity $\mu$

エマルジョン相内を䚌拌することにより清澄水の流出 挙動は変化する．㩭拌の効果は電極間隔 $H$ が小さい場 合ほど顕著に現れる。すなわち，Fig．5 (a) に示すよう に無㹂拌時の解乳化速度 $(=\mathrm{d} Q / \mathrm{d} t)$ は小さくまた解乳化 率も30\% 程度で頭打ちを示すが，㩭汼を加えることに より解乳化速度も最終解乳化率も共に増大寸る. 筧拌速 度 $50 \mathrm{rpm}$ 程度で初期解乳化速度は最大值を示し，また 長時間にわたって一定の解乳化速度を示す．筧拌速度を さらに増すと,初期解乳化速度はわずかに減少するが, 途 中で解乳化速度の急増が見られる. Fig. 5 (b) に示した $H$ が大きい場合には，無㔣拌時の最終解乳化率も $90 \%$ 程度まで増大し，㩭拌の効果はあまり顕著には現れない ことがわかった。

以後の実験では，㩭挥速度を一律に $50 \mathrm{rpm}$ とし，清 澄水の初期生成速度をむってその土マルジョンの解乳化 速度 $V$ と定義した。

本報では, ケロシン溶液で希䣋した W/O エマルジョ ンの解乳化速度に及ぼす分散相体積分率 $\phi$, 平均粒径 $\tilde{d}_{p}$, 電極間隔 $H$, 印加電圧 $E$ などの効果について実験的に 検討し，以下の結果を得た。

\section{$3 \cdot 1$ 分散相体皘分率 $\phi$ の影響}

希釈法によって得られる粒径分布が同じで $\phi$ のみが異 なるエマルジョンについての実験結果から，解乳化速度 $V$ の $\phi$ 依存性を示すFig. 6 を得た. $\phi$ が小なるほど解乳 化速度は大である. 印加電圧が高い場合には， $\phi=0.3 \sim$

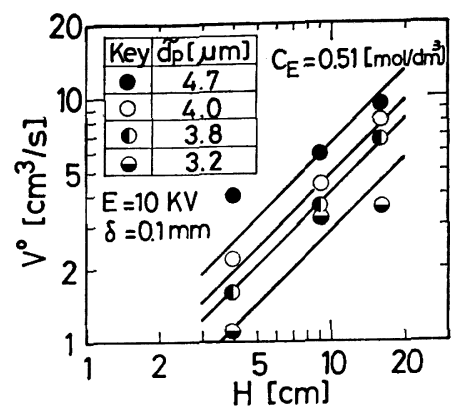

Fig. 8 Effect of the distance between electrodes $H$ on

0.5 の間で解乳化速度の急激な低下が生じる. 低電圧の 場合, その変化は緩やかである. 本研究では $V$ と $\phi$ との 直接的相関を得ることは困難であった. しかし，Fig. 3 に示したェマルジョンの粘度との相関を試みたところ, 本実験のほとんどすべての結果が Eq. (2) の形で相関で きた. Eq. (2) による相関例を Fig. 7 に示す.

$$
V=V^{\circ}\left(\frac{\mu^{*}-\mu}{\mu^{*}-\mu_{c}}\right)
$$

なお $V^{\circ}$ は $\mu \rightarrow \mu_{c}$ ，すなわち $\phi \rightarrow 0$ ，における仮想的な 解乳化速度であり， $\mu^{*}$ は直線と横軸 $(V=0)$ との切片 で定義される仮想的な最大粘度である.

$\phi$ が大で，その粘度が $\mu^{*}$ よりも大きいェマルジョン の解乳化速度は極めて小さい. しかし, このエマルジョ ンをケロシン溶液で希釈して $\phi$ (同時に $\mu$ ) を減少させ れば Eq. (2) に従って解乳化が進行する.

本実験系での解乳化速度に及ぼす $\phi$ の影響は粘度を介 して Eq. (2) で表されることがわかったので, 式中の パラメータ $V^{\circ}, \mu^{*}$ に及ぽす $\phi(\mu)$ 以外の諸因子の影響 について検討した.

\section{$3 \cdot 2$ 電極間隔 $H$ の影響}

$\tilde{d}_{p}$ 一定の試料についての実験結果を Eq. (2) で相関 し， $V^{\circ}$ に及ぼす $H$ の影響を調べた，結果を Fig. 8 に示す。なお $H$ は $\mu^{*}$ の值には影響を及ぼさないこと がわかった．したがって本実験の範囲 $(H=4 \sim 16 \mathrm{~cm})$ では, 一定印加電压のもとでの解乳化速度はみかけの電 界強度 $(E / H)$ の值には無関係に, 電極間隔に比例して 增大寸る.

$$
V^{\circ} \propto H
$$

\section{$3 \cdot 3$ 平均粒径 $\tilde{\boldsymbol{d}}_{p}$ の影響}

乳化時の㨨拌時間 $\theta$ を变えて作製した平均粒径の異な る4 種類の陚料による実験結果を Fig. 9 に示す. 同図 から，次の関係が得られる.

$$
\begin{aligned}
& V^{\circ} \propto \tilde{d}_{p}{ }^{3} \\
& \mu^{*} \propto \tilde{d}_{p}{ }^{-1 / 3}
\end{aligned}
$$

ガラス電極の 厚さが異なる 場合にも同じ相関が 得られ 


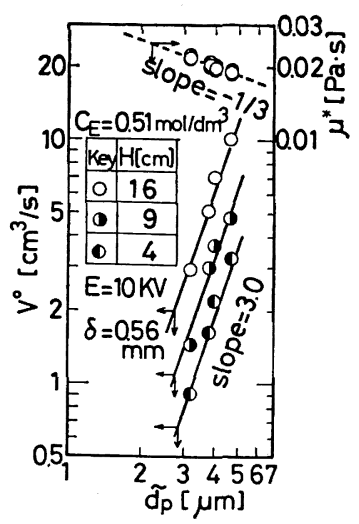

Fig. 9 Effects of the average diameter of dispersed water droplets on $V^{\circ}$ and $\mu^{*}$

る. 解乳化速度の平均粒径依存性は極めて強い。

\section{$3 \cdot 4$ 印加電圧 $E$ の影響}

$H=9 \mathrm{~cm}, \tilde{d_{p}}=3.2 \mu \mathrm{m}$ での $V^{\circ}$ と $E$ との関係を

Fig. 10 に示す. 図から次の関係が得られる.

$$
\begin{aligned}
& V^{\circ} \propto E^{n} \quad n=0.5\left(E<E_{T}\right), \quad n=2.0\left(E_{T}<E\right) \\
& \mu^{*} \propto E^{-1 / 3}
\end{aligned}
$$

指数 $n$ の値は $E_{T}$ を境に 0.5 から 2.0 へと变化する傾 向が見られた. この遷移電圧 $E_{T}$ の值はガラス電極の厚 さ $\delta$ か $0.56 \mathrm{~mm}$ の場合には約 $8 \mathrm{kV}, 0.1 \mathrm{~mm}$ の場合 には約 $6 \mathrm{kV}$ であり， $\delta$ の減少とともに低下寸る，一定 印加電圧のもとでの解乳化速度は， $\delta$ が小さいほど大き な値を示す. しかし， $\delta$ が $0.1 \mathrm{~mm}$ 以下になると電圧 印加時に電極が破壊され易くなるため実用的でない。

\section{$3 \cdot 5$ 分散相中の電解質濃度の影響}

Fig. 6 中に示した実験結果から, 分散相中の電解質濃 度が高いほど解乳化速度は大きくなることがわかる．同 因には示さなかったが，分散相を純水にした場合にはそ の解乳化速度は極めて小さくなった．また同図中に示し た $\mathrm{HCl}$ 水溶液を分散相とするエマルションンの解乳化速 度を，等濃度の食塩水の場合のそれと比較すると低 $\phi$ 域 では小さく，高 $\phi$ 域では大きな值を示している。このよ らな, 分散水相中に存在する電解質の種類や濃度による 解乳化速度の変化については今後さらに検討する必要が ある.

\section{$3 \cdot 6$ 電 流 量}

本装置内を流れる電流量は解乳化に要するエネルギー 量を知るためにも必要な情報である.

通電開始直後から残留分散水相体積分率が大略 0.05 程度に低下するまでの間の電流値 $i$ は Eq. (8) で概算 できる. 解乳化が進行し残留分散水相体積分率が約 0.05 程度に低下すると，電流は Eq. (8) の 1/4 1/5 以下に 急減し, 同時に槽底加らの清澄水流出速度も急激に減少 する。

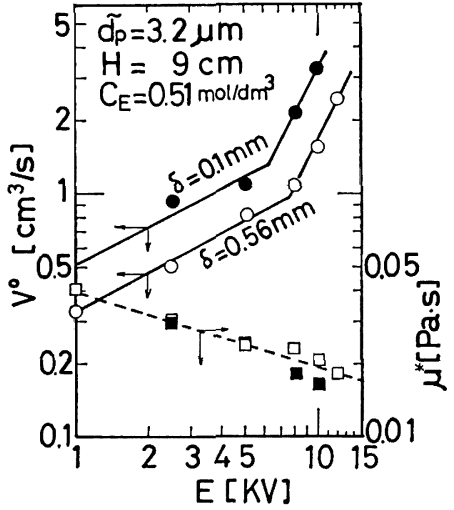

Fig. $10 \quad$ Effects of the applied AC potential on $V^{\circ}$ and

$$
i=\frac{E}{Z}
$$

ここで $Z$ はガラス電極のインピーダンスである. パイ レックスガラスの電気伝導度は極めて小さいため, $Z$ は リアクタンスのみで定まる。ガラス電極の電気容量を $c_{e}[\mathrm{~F}]$, 電源周波数を $f[\mathrm{~Hz}]$ とするとき $Z \fallingdotseq 1 /\left(2 \pi f c_{e}\right)$ である. 例党ば, $\delta=0.1 \mathrm{~mm}$ のガラス電極の $50 \mathrm{~Hz}$ の 交流に対するインピーダンス $Z$ は約 $11 \mathrm{M} \Omega$ と推算さ れる. 印加電圧 $E=10 \mathrm{kV}$ の場合の実測電流值は約 1 mA であり, Eq. (8) の結果とほぼ一致した.

電流量がガラス電極のリフクタンスのみで決まること は, 電極間隔を変えてもェマルジョンの種類を变えても 電流量はあまり変化しないといら実験事実とも対応して いる．さらに，対極である食塩水面位を故意に上昇させ ガラス電極を沈め込んだ場合 (短絡状態に相当する)にも 電流值は変化しない事実も説明できる。このことから， 交流高電圧電源とガラス電極を組み合わせる方法は電気 的に極めて安全性の高いものであることがわかった。

Eqs. (2) (7) の結果から, 本実験に使用した W/O エ マルジョンの解乳化速度 $V$ に対して

ただし，

$$
V=A \cdot H \cdot E^{n} \cdot \tilde{d_{p}}{ }^{3} \cdot\left(\frac{\mu^{*}-\mu}{\mu^{*}-\mu_{c}}\right)
$$

$$
\begin{aligned}
\mu^{*} & =B \cdot \tilde{d}_{p}^{-1 / 3} \cdot E^{-1 / 3} \\
n & =0.5\left(E \leqq E_{T}\right), \quad n=2.0\left(E_{T}<E\right)
\end{aligned}
$$

なる相関が得られた. Eqs. (9)，(10) 中の未定の比例定 数 $A, B$ はさらに多くの因子の関数であると思われる.

$\mathrm{W} / \mathrm{O}$ エマルジョンの電気的解乳化の主原因は, 電界 中に置かれた各水滴に誘起される電気双極子間の相互作 用による水滴間引力 ${ }^{4,6)}$ であろらと推察される. しかし この機構による W/O エマルジョンの解乳化速度の定式 化は今後さらに検討する必要がある.

乳化液膜抽出法に使用する $\mathrm{W} / \mathrm{O}$ エマルジョンの分散 水相の滴径は, 抽出時のエマルジョンの破壊率や物質移 
動速度に及ぼす影響などをも考慮して最適値を定める必 要がある. しかし, 解乳化の容易さの観点からは, 分散 水相の滴径は大きいほど好ましいといえる。また，解乳 化速度の粒径依存性が極めて大きいことから, 連続操業 時に油相中に微小水滴が蓄積する可能性が考えられる. 本実験装置の型式では, ケロシン溶液中に乳化している $1 \mu \mathrm{m}$ 以下の微小水滴を除去することは困難であり, 多 段化もしくは他の方法との併用を考えねばならない。こ れら回収工程の複雑化を防ぐためには, 微細粒子の発生 量の少ない乳化装置を選定することも必要である.

\section{結言}

乳化液膜を用いる抽出操作に拈いて, 抽出液回収工程 の成否を決める $\mathrm{W} / \mathrm{O}$ エマルジョンの解乳化操作の基礎 的資料を得ることを目的として，Span 80 で安定化され たケロシンー食塩水系のエマルジョンに, 交流高電压をガ ラス電極を介して印加する解乳化方法について実験的検 討を行った。 その結果, 下記の事項が明らかになった.

1）本実験の試料エマルジョンは遠心力や加熱などの 方法では解乳化され難いが，交流高電圧を印加すると急 速に破壊され清澄な水相を得ることができる.

2）本実験の試料エマルジョンの解乳化速度に及ぼす 主要因子の影響は Eqs. (9), (10) で表される.

3) ガラス電極と交流高電圧電源を用いる方法は, 液 面位置の変動に対しても過大電流の発生の恐れもなく， 電気的に安全な装置を構成することができる.

\section{Nomenclature}

\begin{tabular}{|c|c|c|}
\hline & $\begin{array}{l}=\text { concentration of electrolyte in the } \\
\text { dispersed phase }\end{array}$ & {$\left[\mathrm{mol} / \mathrm{dm}^{3}\right]$} \\
\hline & capacitance of the glass electrode & [F] \\
\hline & $\begin{aligned} &= \text { diameter of the dispersed water } \\
& \text { droplet }\end{aligned}$ & {$[\mu \mathrm{m}]$} \\
\hline & $\begin{aligned}= & \text { average diameter of the water } \\
& \text { droplets }\end{aligned}$ & \\
\hline & applied AC potential & \\
\hline
\end{tabular}

$E_{\tau} \quad=$ transition potential

$F \quad=$ volume fraction of the droplets with diameters between $d_{p}-\Delta d_{p} / 2$ and $d_{p}+\Delta d_{p} / 2$, where $\Delta d_{p}$ is $1 \mu \mathrm{m}$

[ $\left.\mu \mathrm{m}^{-1}\right]$

$f=$ frequency of the applied $\mathrm{AC}$

$g \quad=$ gravitational acceleration

$H=$ distance between electrodes

$i=$ electric current

$Q \quad=$ volume of the demulsified clear water $\left[\mathrm{m}^{\mathrm{j}}\right]$

$t=$ time elapsed under application of AC potential

$V \quad=$ demulsifying rate $(=d Q / d t)$ $\left[\mathrm{m}^{3} / \mathrm{s}\right]$

$V^{\circ}=$ supposed demulsifying rate at $\phi \rightarrow 0$, see Fig. 7

$v_{0}=$ volume of the initially loaded emulsion

$Z \quad=$ impedance of the glass electrode

$\delta \quad=$ wall thickness of the glass electrode [mm]

$\theta \quad=$ running time of the emulsifier [s]

$\mu \quad=$ viscosity of emulsion $\quad[\mathrm{Pa} \cdot \mathrm{s}]$

$\mu_{c}=$ viscosity of the oil phase $\quad[\mathrm{Pa} \cdot \mathrm{s}]$

$\mu^{*} \quad=$ fictitious maximum viscosity of emulsion, which is obtained from Fig. 7

$\phi \quad=$ volume fraction of water in the emulsion

〈subscripts〉

$\mathrm{E} \quad=$ electrolyte

$0=$ initial value

\section{Literature cited}

1) Kitagawa, T. and A. Ishihara: Preprint of the 45th Annual Meeting of The Soc. Chem. Engrs. Japan, Osaka (1980)

2) Martin, T. P. and G. A. Davies: Hydrometallurgy, 2, 315 (1976/1977)

3) Mooney, M.: J. Colloid Sci., 1, 195 (1946)

4) Waterman, L. C.: Chem. Eng. Progr., 61, 51 (1965)

5) Waterman, L. C. and J. D. Winslow: IEEE. Intern. Conv. Record, 14, 9 (1966)

6) Zebel, G.: Staub, 23, 263 (1963)

(1982 年 5 月 6 日受理; 化学工学協会第 15 回秋季大会 (金 沢, 1981 年 10 月) にて発表) 


\title{
Demulsification of W/O Emulsion under Applied AC Potential
}

\author{
Hajime Ino \\ Gunma Tech. College., Maebashi 371 \\ Nobuyuki Imaishi, Mitsunori Hozawa and Katsuhiko Fujinawa \\ Chem. Research Inst. of Non-Aqueous Solutions, Tohoku Univ., Sendai 980
}

The bottleneck of $\mathrm{W} / \mathrm{O} / \mathrm{W}$ emulsion extraction seems to lie in its final stage, i.e. the breaking of $\mathrm{W} / \mathrm{O}$ emulsion (demulsification). This work was undertaken to ascertain the feasibility of the $\mathrm{AC}$ electrical method for the demulsification and to clarify the fundamental characteristics of the method.

The W/O emulsions used were made from an aqueous solution of $\mathrm{NaCl}$ and kerosene, dissolving 4 vol\% of Span 80 with a rotary disperser. The average diameters of the dispersed water droplets, $\tilde{d}_{p}$, were in the range of $3.2 \sim 4.7 \mu \mathrm{m}$. The emulsions were found to be stable in both a centrifugal demulsification test and a thermal one.

The applications of AC potential of $1 \sim 12 \mathrm{kV}$, between a nonconductive electrode of glass in the emulsion layer and the underlying water layer, caused a marked decrease in emulsion stability, and a clear water layer was formed. The throughput rates $V$ of the clear water were expressed as

$$
\begin{aligned}
& V \propto H \cdot E^{n} \cdot \tilde{d}_{p}^{3} \cdot\left(\frac{\mu^{*}-\mu}{\mu^{*}-\mu_{c}}\right), \quad n=\left\{\begin{array}{l}
0.5 \text { for } E<E_{T} \\
2.0 \text { for } E>E_{T}
\end{array}\right. \\
& \mu^{*} \propto E^{-1 / 3} \cdot \tilde{d}_{p}{ }^{-1 / 3}
\end{aligned}
$$

where $H$ is the distance between electrodes, $E$ the applied AC potential, $\mu$ the viscosity of the emulsion, $\mu_{c}$ the viscosity of the oil phase and $E_{T}$ the transition potential, which is in the range of $6 \sim 8 \mathrm{kV}$.

In conclusion, the $\mathrm{W} / \mathrm{O}$ emulsion can be broken by the $\mathrm{AC}$ electrical method, provided that the diameter of the water droplets is larger than $1 \mu \mathrm{m}$. 